\title{
Formaldehyde and the risk of squamous cell carcinoma of the sinonasal cavities
}

\author{
J H OLSEN, ${ }^{1}$ S ASNAES ${ }^{2}$
}

From the Danish Cancer Registry, ${ }^{1}$ Institute of Cancer Epidemiology, Under the Danish Cancer Society, and Institute of Forensic Medicine, ${ }^{2}$ DK-2100 Copenhagen 0, Denmark

\begin{abstract}
A study of 759 histologically verified cancers of the nasal cavity (287 cases), paranasal sinuses ( $179^{\circ}$ cases), and nasopharynx (29.3 cases) and 2465 cancer controls diagnosed in Denmark between 1970 and 1982 was conducted to investigate the importance of occupational exposure to formaldehyde. Information on job history for cases and controls was derived from a national data linkage system and exposure to formaldehyde and wood dust was assessed by industrial hygienists unaware of the case-control status of the patients. The exposure rates for formaldehyde among male and female controls were $4.2 \%$ and $0 \cdot 1 \%$, respectively. After proper adjustment for contemporary wood dust exposure, relative risks of $2 \cdot 3(95 \% \mathrm{CI}=0 \cdot 9-5 \cdot 8)$ for squamous cell carcinoma and $2 \cdot 2$ $(95 \% \mathrm{CI}=0 \cdot 7-7 \cdot 2)$ for adenocarcinoma of the nasal cavity and paranasal sinuses were detected among men who have ever been exposed to formaldehyde in their job compared with those never exposed. The introduction of a 10 year latency period did not change the risk estimates substantially. It was considered unlikely that the results were due to bias or misclassification of exposure although the effect of chance could not be excluded.
\end{abstract}

Recent case-control studies suggest that formaldehyde may be a human carcinogen in concentrations that were present in workplaces in the past. Relative risks of 1.6 and 2.5 for cancers of the nasal cavities and paranasal sinuses have been assessed in subjects who have been occupationally exposed to formaldehyde. ${ }^{12}$ Formaldehyde is genotoxic in several assays $^{3}$ and is carcinogenic for rats and probably for mice, producing nasal tumours after inhalation. ${ }^{45}$ Even though the histological subgrouping of the experimentally induced tumours has later given rise to some criticism, ${ }^{6}$ it is generally agreed that it is the squamous cell carcinoma that predominates in these long term exposure studies. Human as well as experimental evidence, however, needs further evaluation to qualify and quantify the risk of nasal cancer in man after exposure to formaldehyde.

This paper reports on a case-control study to investigate the risk of squamous cell carcinomas and adenocarcinomas of the nasal cavities developing after occupational exposure to formaldehyde and wood dust. The excess risk of developing a tumour at these sites has been reported without distinguishing

Accepted 18 December 1985 between the histological subgroups. ${ }^{1}$ Recently the histology of the tumour has been verified among the cases and a reanalysis performed.

\section{Material and methods}

Cases and controls were selected from the files of the Danish Cancer Registry ${ }^{17}$ which is a computerised register based on notification forms filled out by physicians (or in case of necropsy, by pathologists) at the time of diagnosis and forwarded to the Cancer Registry.

\section{CASES}

The case group consists of all patients with cancer of the nasal cavity (ICD-7: 160.0), paranasal sinuses (ICD-7: 160.2-160.9), and nasopharynx (ICD-7: 146) diagnosed in Denmark between 1970 and 1982, a total of 839 subjects (table 1). The original notification forms were found in the archives of the registry and examined for futher information on tumour diagnosis. Approximately $90 \%$ of the notification forms stated exactly the site and histology of the tumour. In cases where no information on histology could be obtained from the forms or where uncertainties as to the reliability of the morphology or 
Table 1 Verification of tumour site and histology

\begin{tabular}{llrr}
\hline ICD-71 & Verification & No & \multicolumn{1}{c}{$\%$} \\
\hline \multirow{2}{*}{$160 / 146$} & Miscoding in Cancer Registry & 41 & 5 \\
Tumour site and histology confirmed & 759 & 90 \\
160/146 & Benign tumour & 3 & 0 \\
& Histology not stated & 29 & 4 \\
& Not primary cancer & 7 & 1 \\
& & 839 & 100 \\
\hline
\end{tabular}

primary site of tumour persisted, inquiries were forwarded to the hospital departments that had treated the patients and to the pathology institutes for verification of the site of the tumour and its histology.

As shown in table 1, 5\% of the tumours had been incorrectly coded to the sinonasal cavities and nasopharynx. Most of these tumours were, in fact, skin cancers of the nostrils and external nose. In addition it appears (table 1) that $1 \%$ of the cases were secondary tumours that had spread to the upper respiratory tract. Finally, verification was not obtained in $4 \%$ of cases. So, after appropriate exclusion of cases, 759 histologically verified cancers of the nasal cavity ( 287 cases), paranasal sinuses (179 cases), and nasopharynx (293 cases) remained for analysis.

\section{CONTROLS}

About three times as many controls as cases were selected among patients with cancer of the colon, rectum, prostate, and breast diagnosed during the same period. ${ }^{1}$ The control group was selected to be similar to the case group with regard to sex, age ( \pm 5 years), and year of diagnosis ( \pm 5 years). Altogether 2465 individuals were included as controls and remained included irrespective of the re-examination of the cases described above.

\section{ASSESSMENT OF EXPOSURE}

By means of record linkage of the information on the malignancy derived from the Cancer Registry with information on employment and job titles included in a so called Supplementary Pension Fund and in the Danish Central Population Registry, an occupational history dating back to 1964 was established for each case and control. The Supplementary Pension Fund is
Table 2 Normal and restricted ( $R$ ) stratification for wood dust exposure used in the analysis of risks associated with exposure to formaldehyde

\begin{tabular}{|c|c|c|}
\hline Normal stratification & $\begin{array}{l}\text { Registered exposure } \\
\text { categories }\end{array}$ & $\begin{array}{l}\text { Restricted }(R) \\
\text { stratification }\end{array}$ \\
\hline $\begin{array}{l}\text { Exposed } \\
\text { Unexposed }\end{array}$ & $\left\{\begin{array}{l}\text { LIKELY } \\
\text { POSSIBLE } \\
\text { UNKNOWN } \\
\text { UNLIKELY }\}\end{array}\right.$ & $\begin{array}{l}\text { Exposed (R) } \\
\text { Unexposed (R) }\end{array}$ \\
\hline
\end{tabular}

a compulsory national pension scheme that covers all employees in the country, and the Central Population Registry is a national roster that comprises job description by title for most inhabitants and which is updated daily.

All occupational histories were reviewed, without knowledge of case-control status, by three industrial hygienists trained in the assessment of chemical exposure in Danish industries. For each single employment it was determined whether cases and controls (1) had remained unexposed to formaldehyde and wood dust, (2) had been exposed with certainty, (3) had probably been exposed, or (4) whether no information on exposure could be obtained. The guidelines for the assessment of exposure and the data linkage have been described in detail elsewhere. ${ }^{1}$

\section{ANALYSIS}

The effect of exposure to formaldehyde and wood dust on the risk of cancers of the nasal cavity and paranasal sinuses and cancer of the nasopharynx has been estimated as an odds ratio; $95 \%$ confidence limits were calculated as outlined by Miettinen. ${ }^{8}$ When subjects were stratified according to exposure in order to take possible confounding into account, the Mantel-Haenszel procedure for calculating summary estimates of the relative risk was used. ${ }^{9}$

In the calculation of the risk of cancers of the nasal cavity and paranasal sinuses associated with formaldehyde exposure, two alternative procedures for the stratification of wood dust exposure have been followed (table 2). The first has been performed to preserve the best possible power of the study and the

Table 3 Frequency (\%) of tumours according to histology and site. (Percentages given in parentheses)

\begin{tabular}{|c|c|c|c|c|}
\hline & \multicolumn{2}{|c|}{ Nasal cavity and paranasal sinuses } & \multicolumn{2}{|c|}{ Nasopharynx } \\
\hline & Men & Women & Men & Women \\
\hline \multirow[t]{2}{*}{$\begin{array}{l}\text { Squamous cell carcinoma \& lymphoepithelioma } \\
\text { Adenocarcinoma } \\
\text { Sarcoma } \\
\text { Malignant melanoma } \\
\text { Other histology }\end{array}$} & $\begin{array}{l}215(69) \\
39(13) \\
17(6) \\
16(5) \\
23(7)\end{array}$ & $\begin{array}{c}103(66) \\
13(8) \\
21(13) \\
4(3) \\
15(10)\end{array}$ & $\begin{array}{l}159(80) \\
6(3) \\
28(14) \\
0(0) \\
6(3)\end{array}$ & $\begin{array}{l}66(70) \\
2(2) \\
19(20) \\
0(0) \\
7(8)\end{array}$ \\
\hline & $310(100)$ & $156(100)$ & $199(100)$ & $94(100)$ \\
\hline
\end{tabular}


Table 4 Adjusted, separate, and joint relative risk (RR) among men for squamous cell carcinoma of the nasal cavity and paranasal sinuses after exposure to formaldehyde and wood dust ( $A$ : ever versus never exposed; $B: 10$ or more years since first exposure)

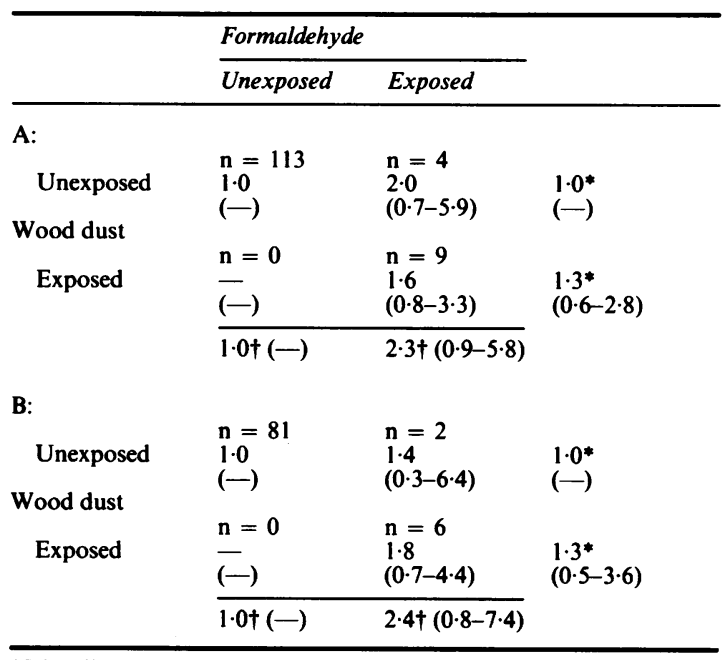

* $R R$ adjusted for formaldehyde exposure.

t $R R$ adjusted for wood dust exposure

other to ensure that no residual confounding effect from wood dust exposure persisted. The calculations were performed using the programs developed by Rothman and Boice. ${ }^{10}$

\section{Results}

The exposure ratios for formaldehyde and wood dust among controls were found to be $4.2 \%$ and $5.8 \%$, respectively, for men, and $0.1 \%$ and $0.0 \%$ for women.

Table 3 shows the distribution of the 759 tumours of the nasal cavity, paranasal sinuses, and nasopharynx according to histology. Squamous cell carcinomas predominate, accounting for $72 \%$ of the cases. Some $8 \%$ are adenocarcinomas and $20 \%$ sar: comas, melanomas, and tumours of more rare histological origins.

\section{CARCINOMAS OF THE NASAL CAVITY AND PARANASAL SINUSES (ICD- 7:160.0,} $160 \cdot 2-160 \cdot 9)$

Table 4 shows the relative risk of squamous cell carcinomas of the nasal cavity and paranasal sinuses developing in men after exposure to formaldehyde or wood dust (ever versus never exposed (A), and after the introduction of a latency period of at least 10 years from first exposure till tumour diagnosis (B)). The adjusted excess risks for these tumours were $2 \cdot 3$ whenever exposed to formaldehyde and 1.3 whenever exposed to wood dust. The joint relative risk was $1 \cdot 6$. None of the risk estimates, however, was significantly greater than one. The introduction of a 10 year latency period did not change the risk estimates substantially.

The effect of formaldehyde and wood dust exposure on the occurrence of adenocarcinomas of the nasal cavities is examined in table 5. A significant excess risk of 16.3 was detected for wood dust exposure after proper adjustment for formaldehyde exposure was carried out (A), and a nonsignificant excess risk of $2 \cdot 2$ was observed for formaldehyde exposure after adjustment for the effect of wood dust exposure. Table 5 also shows the joint effect of formaldehyde and wood dust with an estimated relative risk of 39.5 . In the study population not exposed to wood dust a significant excess risk was observed after exposure to formaldehyde (tables 6 and 7). Inserting a latency period of 10 years (B) did not interfere with this overall pattern for the adenocarcinomas, though the carcinogenic effect of wood dust seemed even more obvious.

In addition to the ordinary procedure of stratification an identical risk analysis has been performed based on a restricted procedure of stratification (table 2) to evaluate possible residual confounding on the results presented. The risk estimates for squamous cell carcinomas are shown in table 6 and those for adenocarcinomas associated with formaldehyde exposure after ordinary and

Table 5 Adjusted, separate, and joint relative risk (RR) among men for adenocarcinoma of the nasal cavity and paranasal sinuses after exposure to formaldehyde and wood dust ( $A$ : ever versus never exposed; $B$ : 10 or more years since first exposure)

\begin{tabular}{ll}
\hline Formaldehyde \\
\cline { 2 - 2 } Unexposed $\quad$ Exposed \\
\hline
\end{tabular}

A:

\begin{tabular}{clll} 
Unexposed & $\mathrm{n}=8$ & $\mathrm{n}=1$ & \\
Wood dust & $1 \cdot 0$ & $7 \cdot 0$ & $1 \cdot 0^{*}$ \\
Exposed & $(-)$ & $(1 \cdot 1-43 \cdot 9)$ & $(-)$ \\
& $\mathrm{n}=2$ & $\mathrm{n}=16$ & \\
& $24 \cdot 0$ & $\begin{array}{l}39 \cdot 5 \\
(7 \cdot 6-75 \cdot 6)\end{array}$ & $(22 \cdot 0-70 \cdot 8)$ \\
\cline { 2 - 3 } & $1 \cdot 0+(-)$ & $2 \cdot 2+(0 \cdot 7-7 \cdot 2)$ &
\end{tabular}

B:

\begin{tabular}{clll} 
Unexposed & $\mathrm{n}=6$ & $\mathrm{n}=1$ & \multirow{2}{*}{$1 \cdot 0^{*}$} \\
Wood dust & $1 \cdot 0$ & $\begin{array}{l}9 \cdot 5 \\
(1 \cdot 6-57 \cdot 8)\end{array}$ & \\
Exposed & $\mathrm{n}=3$ & $\mathrm{n}=11$ & \\
& $36 \cdot 8$ & $44 \cdot 1$ & $30 \cdot 4^{*}$ \\
& $(13 \cdot 5-96 \cdot 0)$ & $(22 \cdot 2-87 \cdot 8)$ & $(8 \cdot 9-103 \cdot 9)$ \\
\cline { 2 - 3 } & $1 \cdot 0+(-)$ & $1 \cdot 8+(0 \cdot 5-6 \cdot 0)$
\end{tabular}

* $R R$ adjusted for formaldehyde exposure. $+R R$ adjusted for wood-dust exposure. 
Table 6 Relative risk ( $R R$ ) for squamous cell carcinoma of the nasal cavity and paranasal sinuses associated to formaldehyde, after "normal" and restricted ( $R$ ) adjustment for wood dust exposure (A: ever versus never exposed; $B: 10$ or more years since first exposure)

\begin{tabular}{|c|c|c|c|}
\hline \multirow[b]{2}{*}{ Wood dust } & \multicolumn{3}{|l|}{ Formaldehyde } \\
\hline & Exposed/unexposed cases & $\boldsymbol{R} R$ & $95 \% C I$ \\
\hline $\begin{array}{l}A: \\
\text { Unexposed } \\
\text { Unexposed }(R) \\
\text { Exposed } \\
\text { Exposed (R) }\end{array}$ & $\begin{array}{l}4 / 113 \\
4 / 111 \\
9 / 1 \\
9 / 0\end{array}$ & $\begin{array}{l}2 \cdot 0 \\
2 \cdot 1 \\
3 \cdot 8 \\
-\end{array}$ & $\begin{array}{l}(0 \cdot 7-5 \cdot 9) \\
(0 \cdot 7-6 \cdot 3) \\
(0 \cdot 5-28 \cdot 4) \\
-\end{array}$ \\
\hline $\begin{array}{l}\text { Adjusted risk } \\
\text { Adjusted risk (R) }\end{array}$ & & $\begin{array}{l}2 \cdot 3 \\
2 \cdot 5\end{array}$ & $\begin{array}{l}(0.9-5 \cdot 8) \\
(0.9-6.8)\end{array}$ \\
\hline $\begin{array}{l}B: \\
\text { Unexposed } \\
\text { Unexposed (R) } \\
\text { Exposed } \\
\text { Exposed (R) }\end{array}$ & $\begin{array}{l}2 / 81 \\
2 / 81 \\
6 / 0 \\
6 / 0\end{array}$ & $\begin{array}{l}1.4 \\
1.4 \\
-\end{array}$ & $\begin{array}{l}(0 \cdot 3-6 \cdot 4) \\
(0 \cdot 3-6 \cdot 4) \\
-\end{array}$ \\
\hline $\begin{array}{l}\text { Adjusted risk } \\
\text { Adjusted risk (R) }\end{array}$ & & $\begin{array}{l}2 \cdot 4 \\
2 \cdot 1\end{array}$ & $\begin{array}{l}(0 \cdot 8-7 \cdot 4) \\
(0 \cdot 6-6.9)\end{array}$ \\
\hline
\end{tabular}

Table 7 Relative risk (RR) for adenocarcinoma of the nasal cavity and parananasal sinuses associated to formaldehyde, after "normal" and restricted $(R)$ adjustment for wood dust exposure (A: ever versus never exposed; B: 10 or more years since first exposure)

\begin{tabular}{llll}
\hline & Formaldehyde & & \\
\cline { 2 - 4 } Wood dust & Exposed/unexposed cases & $R R$ & $95 \% C I$ \\
\hline$A:$ & $1 / 8$ & $7 \cdot 0$ & $(1 \cdot 1-43 \cdot 9)$ \\
Unexposed & $1 / 8$ & $7 \cdot 4$ & $(1 \cdot 2-45 \cdot 8)$ \\
Unexposed (R) & $16 / 4$ & $1 \cdot 7$ & $(0 \cdot 5-5 \cdot 6)$ \\
Exposed & $16 / 2$ & $1 \cdot 3$ & $(0 \cdot 3-7 \cdot 0)$ \\
Exposed (R) & & $2 \cdot 2$ & $(0 \cdot 7-7 \cdot 2)$ \\
Adjusted risk & & $2 \cdot 3$ & $(0 \cdot 4-12 \cdot 0)$ \\
Adjusted risk (R) & $1 / 6$ & & $(1 \cdot 6-57 \cdot 8)$ \\
B: & $1 / 6$ & $9 \cdot 5$ & $(1 \cdot 6-57 \cdot 7)$ \\
Unexposed & $11 / 5$ & $9 \cdot 5$ & $(0 \cdot 5-4 \cdot 5)$ \\
Unexposed (R) & $11 / 3$ & $1 \cdot 3$ & $(0 \cdot 3-5 \cdot 2)$ \\
Exposed & & $1 \cdot 1$ & $(0 \cdot 5-6 \cdot 0)$ \\
Adjusted risk & & 1.8 & $(0 \cdot 4-8 \cdot 4)$ \\
Adjusted risk (R) & & 1.8 & \\
\hline
\end{tabular}

restricted adjustment for wood dust exposure are given in table 7 . It may be seen in the tables that risk estimates remained stable. This is also true for the risk estimates associated with wood dust exposure (not shown here).

Among women the exposure rates for formaldehyde and wood dust were too low to allow for any risk estimation.

CARCINOMAS OF THE NASOPHARYNX (ICD-7:146) Analysis for the risk of histologically specified carcinomas of the nasopharynx did not show any association with either formaldehyde or wood dust exposure.

\section{Discussion}

A previously published analysis of this case-control study showed a non-significant excess risk of 1.6 for carcinomas of the nasal cavity and paranasal sinuses among individuals with occupational exposure for formaldehyde and a significant excess risk of $2 \cdot 1$ for those exposed for wood dust. The results were claimed to be compatible with a weak relation between formaldehyde and sinonasal cancer in man. It was also emphasised, however, that future studies of those associations should include dose response relations, and might gain from separate examination of the different histological types of carcinoma. ${ }^{1}$

The present analysis has been undertaken after obtaining the appropriate information on the specific histological type of carcinoma among the cases. A substantial excess risk of 16 was detected for adenocarcinomas of the nasal cavities after exposure to wood dust which increased to 30 after the inclusion of a 10 year latency period (table 5). These results confirm the observed substantial excess risk of adenocarcinomas among wood workers especially in the furniture industry, reported in earlier studies. ${ }^{11-13}$ 
An effect of wood dust exposure on the risk of developing squamous cell carcinomas was not apparent after a proper adjustment for formaldehye exposure was carried out (table 4).

The raised risks of $2 \cdot 3$ (ever versus never exposed) and 2.4 (10 or more years since first exposed) for squamous cell carcinomas associated with occupational formaldehyde exposure were based on 13 and eight cases exposed to formaldehyde of which only four and two cases, respectively, were unexposed to wood dust (table 4). These risk etimates for squamous cell carcinomas do not reach a level of significance but are remarkably near to the risk estimates found by Hayes et al for squamous cell carcinomas of the nasal cavities after occupational exposure to formaldehyde. ${ }^{2}$

No other epidemiological study gives the risk of adenocarcinoma of the nasal cavities relative to formaldehyde exposure. In this study non-significant risks of $2 \cdot 2$ (ever versus never exposed) and 1.8 (10 or more years since first exposed) were detected among 17 and 12 cases exposed to formaldehyde, respectively (table 5). Owing to the strong relation between exposure to wood dust and nasal adenocarcinoma only one formaldehyde case was observed in the category unexposed to wood dust which indicates that it may be difficult to give an unbiased estimate of the independent influence of formaldehyde on the risk of developing adenocarcinoma of the nasal cavities.

To reduce the possible effect of residual confounding from wood dust in the assessment of the relative risk for formaldehyde a restricted statification procedure for the adjustment of contemporary exposure to wood dust was performed (table 2). The raised risk estimates for squamous cell carcinomas and adenocarcinomas of the nasal cavities were found to be largely unchanged, although the power of the analysis decreased and the risk estimates became even more unstable because of the small numbers. Thus we do not consider that residual confounding from wood dust exposure is an essential problem in the present study. This does not, however, exclude the possibility of misclassification of the exposure to formaldehyde and wood dust. If the exposure under consideration, in casu formaldehyde, is subject to such an unbiased misclassification it would tend to bias the RR estimate towards $1 \cdot 0 .{ }^{14} 15$ In the present study this would mean that the risk estimate was an underestimate of the true relative risk. If it is the confounder, in casu wood dust, which is subject to misclassification this would tend to bias the RR estimate away from 1.0 and accordingly overestimate the true relative risk. ${ }^{16}$ Whereas misclassification of formaldehyde cannot be entirely ruled out because of its widespread use in industry, misclassification of wood dust exposure is not likely to occur as the work of wood processing is well described. It is unlikely, therefore, that the results of the present investigation are due to misclassification of exposures.

Both cases and controls originate from a well defined population and are thus unselected. Occupational histories are obtained from nationwide registries which keep their information for different purposes, and the classification with regard to formaldehyde exposure was undertaken by industrial hygienists with no knowledge of the case-control status of the patients under study. Thus no information bias influences the results. An underestimate of the relative risks might arise if formaldehyde were associated with any of the cancers among the controls; this is unlikely to be the case.

In the present study no information on smoking habit was available. In a case-control study on cases of nasal cancer in North Carolina and Virginia an overall non-significant risk of $20 \%$ was detected in association with cigarette and pipe smoking, ${ }^{17}$ which was most strongly related to squamous cell tumours $(R R=1.8$ for cigarette smoking and 1.5 for pipe smoking). It was stated, however, that the associations found in the study with the occupational variables remained unaffected after controlling for the use of selected tobacco products.

In a similar study performed in the Netherlands ${ }^{2}$ a moderate rise in risk for nasal cancer associated with cigarette use was also detected, but again the adjustment for usual cigarette use did not change the overall risk for nasal cancer associated with formaldehyde exposure. Adjustment for cigarette smoking in the assessment of the risk of squamous cell carcinomas related to formaldehyde did not change the risk estimates essentially. Thus smoking does not seem to be an important confounder in the study of occupationally induced cancers of the nasal cavities and in any case cannot give rise to increased risks of 1.8 to 2.4 seen in association with formaldehyde exposure in the present study.

After the evaluation of the carcinogenicity of formaldehyde by the International Agency for Research on Cancer ${ }^{3}$ several new cohort studies ${ }^{18-22}$ and casecontrol studies 121317 expanding this subject have been published. The cohort studies are all distinguished by a lack of power to detect even moderate excess risks for nasal cancer after occupational exposure to formaldehyde. It is noteworthy, however, that none of the studies reported any deaths due to nasal cancer. ${ }^{23}$ Two of the case-control studies showed a weak statistical association between formaldehyde exposure and nasal cancer, ${ }^{12}$ the remaining two studies were not designed to evaluate the risk of formaldehyde and did not detect one. ${ }^{1317}$

No specified substance or characteristic of wood dust has been identified as a carcinogenic agent. It 
could be argued that the dust may in fact only injure or reduce the natural renewal of the mucous membranes to an extent that facilitates the action of highly water soluble potential carcinogens in the ambient air. If this is true one might expect an effect of formaldehyde in the presence of wood dust only but this is not the case. In addition, the effect of formaldehyde seems to be in the formation of both squamous cell carcinomas and adenocarcinomas, while the effect of wood dust was detectable for adenocarcinomas only.

In conclusion, the present analysis has shown the well known effect of wood dust on the risk of developing adenocarcinomas. An independent risk of occupational formaldehyde exposure on the development of both squamous cell carcinomas and adenocarcinomas was also indicated by the present study. The risk estimates associated with formaldehyde were non-significant; however, this may reflect the lack of power due to the small number of cases exposed only to formaldehyde. An interaction of wood dust and formaldehyde seems to exist on the formation of adenocarcinomas of the nasal cavities. The target organ in experimental animals of the carcinogenic action of formaldehyde is the internal nose. These reports on animal studies taken together with the results of the present epidemiological study and a similar case-control study suggest that formaldehyde may be a human carcinogen.

\section{References}

1 Olsen JH, Jensen SP, Hink H, Faurbo K, Breum NO, Jensen OM. Occupational formaldehyde exposure and increased nasal cancer risk in man. Int $J$ Cancer 1984;34:639-44.

2 Hayes RB, Raatgever JW, de Bruyn A, Gerin M. Cancer of the nasal cavity and paranasal sinuses and formaldehyde exposure. Int J Cancer 1986;37:487-92.

3 International Agency for Research on Cancer. Formaldehyde. In: Monographs on the evaluation of the carcinogenic risk of chemicals to man. Vol 29. Some industrial chemicals and dyestuffs. Lyon: IARC, 1982.

4 Battelle Columbus Laboratories. Final report on a chronic inhalation toxicology study in rats and mice exposed to formaldehyde. Columbus, Ohio: Battelle Colombus Laboratories, 1981.

5 Albert RE, Seelakumar AR, Laskin S, Kischner M, Nelson N,
Snyder CA. Gaseous formaldehyde and hydrogen chloride induction of nasal cancer in the rat. $J$ Natl Cancer Inst 1982;68:597-603.

6 Department of Health and Human Services. Report on the consensus workshop on formaldehyde. Environ Health Perspect 1984;58:323-81. (DHHS publication No (NIH) 84-218.)

7 Danish Cancer Registry. Cancer incidence in Denmark 1978, 1979 and 1980. Copenhagen: Danish Cancer Society, 1983.

8 Miettinen OS. Estimability and estimation in case-referent studies. Am J Epidemiol 1976;103:226-35.

9 Mantel N, Haenszel W. Statistical aspects of the analysis of data from retrospective studies of disease. $J$ Natl Cancer Inst 1959;22:719-48.

10 Rothman KJ, Boice JD. Epidemiologic analysis with a programmable calculator. Washington: National Institute of Health, 1979. (NIH publication No 79-1649.)

11 Acheson ED, Cowdell RH, Rang E. Adenocarcinoma of the nasal cavity and sinuses in England and Wales. Br J Ind Med 1972;29:21-30.

12 International Agency for Research on Cancer. Wood. In: Monographs on the evaluation of the carcinogenic risk of chemicals to man. Vol 25. Wood, leather and some associated industries. Lyon: IARC, 1981.

13 Hernberg S, Westerholm P, Schultz-Larsen K, et al. Nasal and sino-nasal cancer: connection with occupational exposure in Denmark, Finland and Sweden. Scand J Work Environ Health 1983;9:325-6.

14 Bross I. Misclassification in $2 \times 2$ tables. Biometrics 1984;10:478-86.

15 Blettner M, Wahrendorf J. What does an observed relative risk convey about possible misclassification? Methods Inf Med 1984;23:37-40.

16 Tzonon A, Kaldor J, Smith PG, Day NE, Trichopoulos D. Misclassification in case-control studies with two dichotomous risk factors. Rev Epidemiol Sante Publique (in press).

17 Brinton LA, Blot WJ, Becker JA, et al. A case-control study of cancers of the nasal cavity and paranasal sinuses. Am J Epidemiol 1984;119:896-906.

18 Liebling T, Rosenman KD. Pastides H, Graffity RG, Lemenshow S. Cancer mortality among workers exposed to formaldehyde. Am J Ind Med 1984;5:423-8.

19 Walrath J, Fraumeni J. Cancer and other causes of death among embalmers. Cancer Res 1984;44:4638-41.

20 Strayner L, Smith AB, Reeve G, et al. Proportionate mortality study of workers exposed to formaldehyde in the garment industry. Am J Epidemiol 1984;120:458-9.

21 Acheson ED, Gardner MJ, Pannett B, et al. Formaldehyde in the British chemical industry: an occupational cohort study. Lancet 1984; i:611-6.

22 Bertazzi PA, Zochetti C, Pesatori A, Radice L, Vai T. Mortality of workers exposed to formaldehyde in resin manufacturing. Presented at the XXI Congress on Occupational Health, Dublin, Ireland, 1984. Dublin: ETA Publications Ltd, 1985.

23 Scott CS, Margoshes EH. Cancer epidemiology relevant to formaldehyde. Environ Carcinogenesis Revs 1985;3:107-44. 